\title{
RESILIÊNCIA INSTITUCIONAL: para onde vai a participação nos Conselhos Nacionais de Saúde e dos Direitos da Mulher?
}

\author{
Debora Rezende de Almeida*
}

\begin{abstract}
O presente artigo se propõe a compreender as mudanças na participação política que afetaram a relação entre Estado e sociedade civil nos processos decisórios de políticas públicas desde o impeachment presidencial de 2016 no Brasil. Para isso, o artigo propõe o conceito de resiliência institucional, a partir da combinação de quatro literaturas: estudos sobre resiliência, mudança institucional, participação institucional e repertórios de ação coletiva e interação entre Estado e movimentos sociais. Aponta ainda quais seriam os fatores que contribuem para a resiliência de algumas instituições participativas. O trabalho é baseado em estudo de caso dos Conselhos Nacionais de Saúde e Direitos da Mulher, e no uso de técnicas de pesquisa qualitativas, a saber, entrevistas semiestruturadas, observação participante e análise documental, examinando as mudanças nas estratégias e repertórios de interação com o Estado, internamente e para além dos Conselhos, e levantando questões sobre o futuro da participação institucional no país.
\end{abstract}

PALAVRAS-CHAvE: Resiliência institucional, Participação institucional, Conselhos nacionais, Saúde, Direitos das mulheres.

\section{INTRODUÇÃO}

Desde que a Constituição Brasileira de 1988 foi promulgada, os estudiosos de processos de participação têm se dedicado a compreender os seus ganhos e limites nas políticas públicas e na construção democrática (Dagnino, 2002). Porém, o contexto atual, pós-impeachment da presidenta Dilma Rousseff, em 2016, de reorientação das políticas públicas e dos espaços participativos, nos convida a reenquadrar a temática da participação a partir de diferentes perguntas de pesquisa. Este artigo contribui com esta reflexão ao investigar, por um lado, a resiliência institucional, entendida a partir do esforço e ação intencional dos atores para manterem as instituições participativas (IPs) como lócus de atuação, influência e deliberação da sociedade civil sobre os rumos da política. Além de preservar,

* Universidade de Brasília, Campus Universitário Darcy Ribeiro, Instituto de Ciência Política, CEP 70910-900, Brasília - Distrito Federal - Brasil. deborarezende.almeida@ gmail.com

https://orcid.org/0000-0003-4752-8892 os atores precisam defender explicitamente a instituição, por meio da adaptação e ação criativa - improvisação e criação de novas regras e dinâmicas (Lawrence, Suddaby, Leca, 2009; Abers, 2019). Por outro lado, instituições não resilientes (ocaso) seriam aquelas nas quais as atividades são interrompidas ou permanecem formalmente, mas com mudanças profundas nos seus objetivos: por exemplo, deixando de endereçar os problemas para os quais foram criadas, de serem priorizadas pelos atores relevantes e fazerem valer suas práticas (Gordin, Rennó, 2017; Battilana, D’Aunno, 2009). Além de analisar a resiliência institucional das IPs, pretende-se apontar quais seriam os fatores que ajudam a explicá-la ${ }^{1}$.

Apesar da curta distância temporal para

1 Este artigo é resultado de uma pesquisa financiada pelo Edital Universal CNPQ, Processo N. 426882/2016-4. Agradeço aos conselheiros e ativistas da sociedade civil pelas entrevistas e pela luta incansável na defesa da participacão como elemento central da democracia. Também agradeço a participação dos estudantes Mariana Fonseca e Matheus Baccarin, à época bolsistas de iniciação científica, e aos professores Rebecca Abers e Lucio Rennó pela troca de ideias e indicações bibliográficas. Por fim, aos organizadores deste número especial pelos comentários e pareceristas pelos questionamentos que levaram ao refinamento do argumento sobre resiliência institucional. O artigo permanece, porém, de minha inteira responsabilidade. 
a realização de um diagnóstico preciso de conjuntura crítica, parte-se do pressuposto de que não se trata de um simples revezamento na coalizão governamental, mas de um período de transformação dos parâmetros sociais e institucionais que podem gerar reverberações de longa data (Collier e Collier, 2002). O foco nesse período distinto nos permite avaliar como os atores estão reagindo e respondendo ao esforço empreendido por outros atores para perturbar e até mesmo destruir instituições.

$\mathrm{O}$ artigo mobiliza quatro literaturas: estudos socioecológicos sobre resiliência; mudança institucional; participação institucional e análises mais recentes sobre a interação entre movimentos sociais e Estado. A partir destas combinações, apresenta-se o conceito de resiliência institucional, sugerindo ainda que a prática concreta dos atores e a resiliência das Instituições Participativas/IPs só podem ser compreendidas de maneira situada e, para tanto, deve-se levar em conta 3 fatores. O primeiro conjuga duas estruturas relacionais: os subsistemas - comunidades, redes de políticas e arranjos institucionais em determinadas políticas públicas - e o regime político - relação entre atores sociais e políticos sob liderança de uma coalização governante (Abers, Silva e Tatagiba, 2018). Diante da amplitude dos conceitos, dar-se-á atenção à interação dos atores relevantes de um subsistema com distintos - atores partidários e coalizões governamentais na construção da política. Os demais fatores conformam estruturas organizacionais: o desenho institucional e as características do setor de políticas públicas.

O trabalho se beneficiará de uma pesquisa qualitativa realizada em duas instâncias participativas no nível nacional: os Conselhos Nacionais de Saúde (CNS) e dos Direitos da Mulher (CNDM). Além de analisar o percurso histórico de institucionalização destes espaços, o artigo oferece uma fotografia "instantânea” dos últimos três anos (2016-2019), capaz de captar as práticas desenvolvidas. Foram realizadas dezesseis entrevistas semiestrutura- das, numeradas no texto de 1 a 17 , e nove entrevistas com representantes do CNDM, identificadas de 1 a $9^{2}$. Além disso, a autora participou no último ano de seis reuniões do CNS, realizou contato com funcionários de ambos os conselhos e análise de conteúdo das atas e moções emitidas pelo Conselho de Saúde. A descontinuidade nas atividades do CNDM desde 2016 impediu a participação mais direta nas reuniões e acesso a documentos.

O artigo está dividido em três seções. A primeira, apresenta a proposta analítica para compreender a resiliência institucional e os fatores que podem explicá-la. A segunda discute os principais resultados no que diz respeito à resiliência no Conselho Nacional de Saúde e a terceira refere-se ao ocaso do Conselho Nacional dos Direitos da Mulher, atentando para as mudanças e adaptações criativas pós impeachment, considerando os condicionantes dessas transformações. Por fim, apresenta as principais conclusões que resultam da comparação entre os dois setores de políticas.

\section{RESILIÊNCIA INSTITUCIONAL: QUAL CONCEITO E O QUE A EX- PLICA?}

Desde o impeachment presidencial de Dilma Rousseff em 2016, o modelo de provisão das políticas públicas adotado na Carta de 1988 e os espaços participativos a elas associados estão sob ataque direto. Primeiramente, vale lembrar que Michel Temer, então vice-presidente, adotou medidas que transformaram a estrutura do Estado, mesmo antes de finaliza-

2 As entrevistas foram realizadas presencialmente ou por meio de videoconferência, entre os anos de 2017 e 2018. Todas as entrevistas foram gravadas e depois transcritas para análise e, devido à exigência de anonimato, estão armazenadas no computador da autora. Em média, duraram entre 1 hora e 1 hora e 30 minutos. No CNS, foram entrevistados os representantes dos usuários (um deles pertenceu também ao CNDM) e dos trabalhadores. No CNDM, os representantes da sociedade civil que já participaram do conselho em outras gestões ou que renunciaram ao cargo em 2016. 
do o processo de afastamento da presidenta ${ }^{3}$. Segundo, a recomposição dos conselhos e ministérios reacendeu o debate sobre os parâmetros de atendimento das políticas públicas e o papel do Estado no seu provimento. Na Saúde, durante observação participante nas reuniões do CNS, foi notório o embate entre atores sociais e governamentais, por exemplo, em torno de propostas de adoção de Planos de Saúde privados, supostamente mais acessíveis à população. Na política de direitos para as mulheres, houve completa reestruturação da Secretaria de Políticas para as Mulheres (SPM), além do crescimento do discurso conservador nas instituições, contra os direitos e as chamadas políticas de gênero (Abers, Almeida, 2019). Terceiro, o presidente eleito em 2018, Jair Bolsonaro, aprofundou essas mudanças ao restringir a participação nas políticas públicas ou extinguir várias instituições participativas por meio de medidas monocráticas ${ }^{4}$. Apesar destes ataques diretos, as IPs e os atores coletivos que delas fazem parte vêm respondendo às mudanças de maneiras muito distintas. É preciso compreender quais os tipos de mudanças que estão ocorrendo nas IPs no nível federal e se elas apontam para uma resiliência institucional - o que implica em um olhar multidisciplinar a fim de definir o conceito. $\mathrm{O}$ artigo apresenta ainda alguns fatores que explicam as possibilidades de resiliência e, indiretamente, o desmonte ou enfraquecimento de outras.

3 Logo após assumir como presidente interino, Michel Temer apresentou reforma administrativa na qual incluía nomeação de ministros, fusão e extinção de ministérios e alteração da política externa. A chamada PEC dos gastos, EC 95/2016, que altera o regime fiscal do país, também tem impactos diretos na política de saúde. Ela reduz o valor mínimo aplicado, sendo equivalente apenas ao piso do ano anterior corrigido pela inflação, sem qualquer ganho real e com perda do investimento per capta em saúde. Ver BRASIL DEBATE E FUNDACÃO FRIEDRICH EBERT. "Austeridade e retrocesso: impactos sociais da política fiscal no Brasil”. Agosto de 2018.

4 Depois de eleito, o presidente Jair Bolsonaro por meio de Medida Provisória 870 alterou a Lei Orgânica de Seguranca Alimentar e Nutricional, de 2006, levando à extinção do Conselho Nacional de Segurança Alimentar e Nutricional (CONSEA), suspendeu as atividades do Conselho Nacional dos Direitos da Pessoa com Deficiência e via Decreto N. 9.759/2019 extinguiu mais de 50 colegiados de composição paritária com a sociedade civil.
Antes de mais nada, vale notar que o conceito de resiliência está presente em diferentes campos do conhecimento e tem seu desenvolvimento ainda limitado na ciência política. Originado na Ecologia, o conceito descreve a capacidade de um sistema retornar, após um choque externo, para um estado de funcionamento prévio, sem mudar qualitativamente sua estrutura (Hollings, 1973). Apesar de grande imersão no tema e décadas de debates, os estudiosos concordam que o conceito permanece ainda vagamente definido e de difícil operacionalização, tendo em vista tanto a discordância acerca da centralidade, e mesmo desejabilidade, que adquire a noção de persistência ou resistência à mudança ${ }^{5}$, quanto a variedade de visões sobre quais seriam os elementos constitutivos da resiliência, especialmente no que tange à possibilidade dos sistemas - o ambiente físico - se auto-organizarem e adaptarem (McEvoy, Fünfgeld, Bosomworth, 2013; Klein, Nicholls, Thomalla, 2003). Embora os estudos socioecológicos se preocupem com a adaptação das instituições frente a desastres, há uma compreensão muito ampla e "bruta" sobre o processo de mudança institucional e as distintas dimensões envolvidas, focando em processos socioinstitucionais amplos, como a presença de capital social e diferentes recursos (Sjöstedt, 2015; Adger, 2000).

Para superar esta lacuna, na linha proposta por Sjöstedt (2015), sugiro estabelecer uma ponte entre o conceito de resiliência e os estudos da ciência política e da sociologia organizacional sobre mudança institucional. Ademais, proponho aliar este debate com a perspectiva relacional voltada a pensar a institucionalização dos movimentos sociais no Estado, para defender um conceito de resiliência no qual manutenção e adaptação criativa dos atores estão entrelaçadas.

Primeiramente, o deslocamento do de-

5 Para McEvoy et al. (2013), em casos de mudanças climáticas, por exemplo, o retorno ao estado anterior pode caracterizar uma resposta inadequada ou mesmo ser sinônimo de uma má adaptação às mudanças. 
bate neoinstitucionalista focado na estabilidade e continuidade das instituições, para a análise da mudança, passou a considerar o papel das transformações abruptas e dos choques exógenos do contexto socioeconômico sobre as instituições - conjuntura crítica - que geralmente levam a reconfigurações institucionais radicais (Collier e Collier, 2002). Em segundo lugar, aproximando-se da ideia de resiliência institucional, apesar de não preocupados com esta temática, os analistas apostaram que as mudanças ocorrem comumente de modo incremental, e não apenas em momentos críticos, gerando, na maioria das vezes, continuidade e adaptação das regras ${ }^{6}$, sem o regresso total ao seu estado original. Mudanças institucionais ocorrem principalmente por duas causas endógenas: o grau de institucionalização das regras - entendidas como propriedades das instituições relativas à maior ou menor possibilidade de interpretação e cumprimento - e as características do contexto político - a presença de defensores do status quo com maior ou menor poder de veto. A combinação destes fatores influencia os tipos de novos atores que podem emergir e a introdução de mudanças mais ou menos radicais (Falleti, 2010; Mahoney, Thelen, 2010). Os autores se debruçam sobre os agentes da mudança, enquanto a manutenção, ou força das instituições, depende de sua capacidade de imprimir conformidade e aplicação das regras. Apesar do maior foco na ação, as adaptações ou a completa destruição são vistas como resultados da combinação de duas forças que operam sobre novos atores - as regras e o poder de veto de outros atores - definidos vagamente como o contexto político.

Gordin e Renno (2017) apresentam o conceito de resiliência institucional e sugerem modificações qualitativas importantes no que se refere à conjugação entre manutenção

6 Os autores discutem quatro tipos de mudancas. Com exceção da estratégia de displacement, em que há mudança das regras e substituição abrupta ou gradual das instituições, nas demais, layering (introdução de novas regras), drift e conversion (mudança do impacto e interpretação das regras, respectivamente), há continuidade. e adaptação. Primeiro, é preciso considerar os trade-offs da proposta que foca na estabilidade das instituições e capacidade de impor ordem/ comportamento como sinônimo de força. Instituições fortes podem funcionar como "gaiolas” que impedem a inovação. Apesar de se preservarem no tempo, não resolvem os conflitos sociais para os quais foram originalmente pensadas, por exemplo, conflitos distributivos e étnicos; enquanto instituições fracas também podem ser resilientes e fontes de inovação. Em segundo lugar, o conceito de resiliência institucional parte de uma noção de força institucional que leva em conta a capacidade de as instituições se manterem, mas também se adaptarem, reduzindo conflitos e se tornando cada vez mais aceitas. Como fatores de mudança consideram o papel das regras, do contexto e dos atores políticos e seus apoiadores, mas, em diálogo com literatura ideacional e agência criativa (a ser desenvolvida a seguir), enfatizam o papel das ideias e estratégias dos atores - engenheiros ou arquitetos institucionais - para ganhar autoridade prática ${ }^{7}$ (Abers, Keck, 2013). Os casos de resiliência são direcionados às instituições fortes que se mantêm mas geram efeitos perversos na sociedade. As adaptações positivas viriam de experiências recentes, que não se beneficiam de uma arquitetura institucional existente e, portanto, são vistas sob a chave da inovação e não da resiliência - termo que aparece na introdução, mas não é incorporado efetivamente nos demais textos do livro. Outro limite, é que a ideia de arquitetos e empreendedores institucionais que alavancam recursos para mudança, de acordo com a sociologia organizacional ${ }^{8}$, mantém a dualidade agência e estrutura ao apostar em uma concep-

7 Atores e organizações adquirem autoridade prática, ou seja, são capazes de influenciar o comportamento de outras organizações e atores, quando desenvolvem capacidades para resolução de problemas e conseguem mobilizar o reconhecimento público e dos tomadores de decisão.

8 Por razões de espaço e foco este amplo debate não poderá ser explorado aqui. A introdução do livro organizado por Lawrence, Suddaby e Leca (2009) apresenta um bom balanço do campo. 
ção heroica da ação.

Baseado neste campo de estudos, sugiro que a noção de "institutional work" contribui tanto para superar esta dualidade, quanto para propor um conceito de resiliência que considere o esforço dos atores para mudar, mas também para manter as instituições - o qual recebeu menos atenção da literatura. Para Lawrence, Suddaby e Leca (2009, p, 1), “o conceito de trabalho institucional descreve a ação intencional de indivíduos e organizações com o objetivo de criar, manter ou desestruturar/interromper as instituições"9. Criação, manutenção e mudança resultam da ação intencional e esforço deliberado por parte dos indivíduos e organizações, ao invés de serem propriedades das instituições e regras, ou do sistema ${ }^{10}$. Indivíduos e organizações são imersos em contextos sociais e sua ação ocorre dentro de um conjunto de regras institucionalizadas para responder a situações que encontram neste contexto (Lawrence, Suddaby, Leca, 2009; Battilana, D’Aunno, 2009). Essa é uma concepção bem próxima à ideia de agência situada que emerge na perspectiva pragmatista das instituições. A mudança institucional não é apenas um ato de vontade, mas ocorre por meio de atores que se engajam em uma "criatividade situada”, uma vez que a ação é constrangida pelos recursos materiais, simbólicos e relacionais (Joas, 1996). O contexto, na visão pragmatista, não é apenas constrangimento, mas facilitador - fonte de recursos - da ação, ao mesmo tempo que constituído a partir dela (Abers, 2019). Quando confrontados com situações problemáticas, os atores inseridos em estruturas materiais e cognitivas e em interrelação com outros, podem experimentar e apresentar novas soluções. O foco se desloca dos resultados para as práticas ou experiências, pois, as próprias

9 No original: "the concept of institutional work describes the purposive action of individuals or organizations aimed at creating, maintaining and disrupting institutions".

$10 \mathrm{O}$ que não significa dizer que a intencionalidade das práticas corresponde necessariamente aos seus resultados, tendo em vista as consequências não esperadas da ação. instituições são definidas como constituídas pela ação mais ou menos consciente dos seus atores. Outra aproximação é encontrada na ideia de que mudanças não seriam epifenômenos das estruturas, pois os atores estão a todo tempo tentando transformar as instituições, negociar suas características, agindo criativamente e em resposta à ação dos outros (Berk, Galvan, 2013). Porém, enquanto a literatura pragmatista teria um olhar para experimentações e mudanças, a noção de trabalho institucional é útil para pensar as práticas também envolvidas na disputa pela manutenção.

Uma última contribuição à definição de resiliência institucional vem da ressignificação da ideia de contexto político que, na mesma linha apontada acima, deixa de ser analisado como cenário externo à ação, para ser resultado dos agenciamentos recíprocos de diversos atores, redes e instituições (Abers, Silva, Tatagiba, 2018). Trazendo para o debate que nos interessa, esta proposta relacional nos ajuda a pensar as ações e esforços direcionados à criação, manutenção e desestruturação como inter-relacionadas, ou seja, a luta pela manutenção se dá em diálogo constante com aqueles que querem impor sua perda de legitimidade. Por fim, apesar das dinâmicas de manutenção e mudança serem contínuas, originalmente, o conceito de resiliência nos convida a olhar para momentos de choques. Consistente com a proposta relacional, eles aqui não são teorizados como externos, mas a partir de momentos em que as relações tomam formas antagônicas e as ações e instituições estão sendo diretamente desafiadas. Neste contexto, as ações diárias para manutenção, circunscritas ao ajuste de regras já institucionalizadas, são insuficientes. Diante do grau de disputa instaurado, adaptações e improvisações, consideradas por Battilana e D’Aunno (2009) como parte do trabalho institucional para criar instituições, também são adotadas pelos atores que se esforçam para preservar instituições. No caso de instituições híbridas, marcadas pela permeabilidade do Estado aos atores sociais, a alteração 
na estrutura de oportunidades políticas pode levar os movimentos sociais a inovações táticas e à adoção de repertórios de ação coletiva, que embora modulares e historicamente apreendidos, podem ser improvisados e adaptados pelos agentes (Tilly, 2005).

Baseada nestes debates, proponho um conceito bidimensional de resiliência institucional que leve em conta, tanto a ação para manter e preservar, quanto sua capacidade de se adaptar considerando os objetivos da instituição. Primeiro, é preciso avaliar a ação intencional e o esforço dos atores para manter as instituições participativas (IPs) como lócus de atuação, influência e deliberação da sociedade civil sobre os rumos da política, em momentos nos quais sua existência está sendo diretamente ameaçada. Segundo a manutenção envolve a defesa explícita da instituição, adaptação e ação criativa - improvisação e criação de novas regras e dinâmicas (Lawrence, Suddaby, Leca, 2009; Abers, 2019). Nas instituições não resilientes (ocaso) as atividades são interrompidas ou permanecem formalmente, mas com mudanças profundas nos seus objetivos, por exemplo, deixando de endereçar os problemas para os quais foram criadas, de serem priorizadas pelos atores relevantes e de fazerem valer suas práticas (Gordin, Renno, 2017; Battilana, D’Aunno, 2009). Embora seja também possível pensar o trabalho institucional de atores externos no suporte a instituições (Cruz et al., 2016), a análise empírica se concentrará nas práticas empreendidas pelos atores e movimentos sociais nas IPs para responder às ameaças. Os atores oponentes aqui receberão atenção apenas na reconstituição histórica do processo de institucionalização dessas IPs e na menção aos atos voltados às tentativas de mudança das IPs.

Levando em conta a ideia de que a ação é situada, será importante perceber quais os fatores que contribuem para as diferentes práticas. Sugiro combinar a literatura da participação institucional e de movimentos sociais no Brasil que, geralmente, caminham isoladamente, considerando três fatores que condicio- nam os resultados e a capacidade de resiliência das formas institucionais de participação. O primeiro fator refere-se a uma combinação entre dois elementos que Abers, Silva e Tatagiba (2018, p. 23) chamam de estruturas relacionais: o regime ${ }^{11}$ formado "pelos atores, interesses e arranjos institucionais estruturados em torno de determinada coalizão governante", e os subsistemas específicos de políticas públicas, que envolvem comunidades de políticas, redes e arranjos institucionais em um determinado campo de política pública. A definição dos dois conceitos é muito próxima, uma vez que envolvem atores, interesses e instituições, além de muito ampla, e a principal diferenciação entre o regime e subsistemas parece ser o nível de análise. Diante da dificuldade de operacionalização para o estudo empírico, proponho reconstruir a maneira como os atores relevantes de um subsistema político, especialmente, os favoráveis a ela, interagiram com distintos atores partidários e diferentes coalizões governamentais na construção das políticas (Côrtes, 2009; Abers, Serafim, Tatagiba, 2014; Almeida, Cunha, 2016; Pires, Gomide, 2016). Nesse sentido, será importante perceber o esforço contínuo dos atores para criar e manter estas instituições, o que se coaduna com a literatura desenvolvida no país que estudou os processos de institucionalização dos movimentos sociais e os distintos níveis de influência conquistados em subsistemas de políticas públicas. Para além da autoridade de jure do Estado, movimentos sociais podem adquirir autoridade prática (Abers; Keck, 2013), ou arquitetar encaixes institucionais - diferentes pontos de acesso e influência - e conquistar domínios de agência, ou seja, sedimentações institucionais que permitem aos atores dirigir de modo contínuo a seletividade das instituições políticas a seu favor (Gurza Lavalle et al., 11 Na literatura sobre participação institucional esta dimensão foi frequentemente tratada a partir da categoria de vontade política (Avritzer e Navarro, 2003). Mas como destacam as autoras, vontade política é um conceito pouco desenvolvido e com conotação voluntarista. Já a ideia de regime político pretende-se mais completa por focar nas interações entre atores, interesses e instituições. 
2019). Nos casos em que atores sociais conquistaram domínio de agência, como na política de saúde, foi central para a mudança institucional a presença de uma policy community ativa, que apostou e percebeu também como legítima a atuação por dentro de variadas instituições, em diferentes coalizões governamentais (Dowbor, 2019). Embora essa literatura não tenha discutido a capacidade de resiliência institucional, pelo contexto político no qual os estudos de caso foram elaborados, reconhece que os projetos de movimentos sociais nunca estão totalmente seguros devido às incertezas do jogo eleitoral, mais do que isso, que alguns atores reagem e até se antecipam a isso buscando estabelecer vários pontos de acesso ao Estado (Dowbor, 2019). Podemos também cogitar que diante do aumento das incertezas, movimentos deixem de priorizar estes espaços, apoiando-se nas articulações com outros movimentos, nas redes de relações informais e no uso de repertórios de ação coletiva modulares e também singulares (Tilly, 2005).

Não obstante a relevância de se olhar para regimes e subsistemas, cabem duas ponderações à proposta relacional apresentada por Abers, Silva e Tatagiba (2018). Primeiro, ao enfatizarem que a agência é situada, os autores privilegiam os constrangimentos que advêm do poder de outros atores. Embora a noção de recursos apareça fortemente no texto, o desenho institucional estaria subsumido na definição de subsistemas das autoras, sendo subtematizado. Segundo a definição final de subsistema se concentra especialmente nas redes e comunidades de políticas, deixando de lado características importantes do "setor" de política. Sendo assim, pensando que a ação ocorre a partir de um conjunto de regras instituídas, sugiro analisar o papel de duas estruturais/organizacionais que impactam na relação dos movimentos sociais com os subsistemas: a institucionalização da participação - clara definição de funções e competências dos espaços, regras de escolha do presidente, pluralidade na composição, caráter deliberativo ou consultivo etc. -, e o setor de política pública, considerando as seguintes características: orçamento, estrutura burocrática e estatal e natureza da política (Faria, 2007; Côrtes, 2009; Gurza Lavalle, Voigt, Serafim, 2016).

A análise a seguir parte de duas áreas de políticas com longo histórico de interação dos movimentos com o Estado, mas com processo diverso de institucionalização, comunidades de políticas e desenhos institucionais, o que nos permite explorar a complexidade e variabilidade das práticas empreendidas por atores sociais nas IPs, bem como as condições colocadas para a resiliência.

\section{RESILIÊNCIA INSTITUCIONAL NO CONSELHO NACIONAL DE SAÚ- DE}

O setor de saúde se destaca no Brasil pela forte relação entre movimento sanitarista, movimento popular, gestores, acadêmicos ${ }^{12} \mathrm{e}$ os setores de gestão do SUS, construída ao longo de diferentes regimes, e pela disseminação de experiências participativas nos diferentes níveis da Federação. O sucesso da incorporação da participação e das ideias do movimento sanitarista, contudo, é resultado da prévia inserção do movimento sanitário no Estado e sua capacidade de "cavar" espaços, mesmo em regimes inicialmente pouco porosos à participação. As conexões profissionais, acadêmicas e partidárias, principalmente com o Partido Comunista Brasileiro (PCB) e com o Movimento Democrático Brasileiro (MDB), possibilitaram a entrada de seus atores sociais nos cargos dirigentes no nível federal, ainda durante o período da ditadura militar, facilitando a introdução de elementos reformistas no Estado (Falleti, 2010; Dowbor, 2019). Vale destacar que o movimento não buscava apenas apoio dos atores 12 Destaque para a criação de departamentos de medicina preventiva nas universidades (1968), e criação do (CEBES) Centro Brasileiro de Estudos de Saúde (1976), e da (ABRASCO) Associação Brasileira de Saúde Coletiva (1979). 
governamentais, mas teria ocorrido uma mútua constituição entre eles por meio da organização da ação coletiva dos ocupantes das secretarias municipais - interessados em acessar mais recursos - e montagem de uma estrutura federativa de organizações que permitiu arquitetar sua inserção no processo decisório da política (Dowbor, 2019). Nos estados, paulatinamente, os secretários de saúde se fortaleceram perante a burocracia nacional de saúde e seguridade social ${ }^{13}$ e criação do Conselho Nacional de Secretários de Saúde, CONASS, em 1982 (Escorel et al., 2005). Após a VIII Conferência Nacional em 1986, não apenas os Conselhos de Saúde se estabeleceram, como também o Conselho Nacional de Secretários Municipais de Saúde (Conasems) e os conselhos estaduais (Cosems), que passariam a atuar desde 1993 nas Comissões Intergestoras Tripartites (CITs) e Bipartites (CIBs).

Para além da estratégia de ocupação de cargos e alianças com atores políticos em diferentes níveis federativos, é notória a atuação junto a partidos políticos, incluindo o Partido dos Trabalhadores (PT), durante a Constituinte e para a aprovação dos normativos do setor da saúde que regulamentam o SUS e a participação social. A elaboração da Lei Orgânica da Saúde (LOS), a Lei 8.080 de criação do SUS, e a Lei 8.142, que regula a participação no sistema por meio de conselhos e conferências, tornam $\cdot$ os conselhos obrigatórios para transferência de recursos aos entes federados ${ }^{14}$. Além disso, a paridade estabelecida nestes espaços sobrerrepresenta os interesses da sociedade, com $50 \%$ da composição de usuários, $25 \%$ de trabalhadores e $25 \%$ divididos entre prestadores privados e públicos. Os conselhos possuem funções claramente definidas no arcabouço mais geral da política e têm caráter deliberativo, do nível

13 Especialmente a partir do Programa de Interiorização das Ações de Saúde e Saneamento (PIASS), de 1979.

14 O CNS existe desde 1937, como órgão de assessoria aos ministérios ligados à saúde, após 1990 é remodelado com base nos princípios do controle social a partir de longa negociação do movimento com o Ministério da Saúde. local ao nacional.

Ao tempo em que se criava o setor público de saúde na Constituição de 1988, o campo privado, já fortemente organizado se mantém, estabelecendo um sistema dual, que depois é formalizado na Lei N. 9665/1998, que regulamenta os planos e seguros privados de saúde (Labra, 1993; Menicucci, 2007). Apesar do cabo de guerra com o setor privado, nos anos 1990, a política de saúde avança tanto na municipalização e descentralização do sistema, quanto na implementação de conselhos (Gurza Lavalle, Barone, 2015). O Brasil saiu de um dos piores sistemas de saúde do mundo em desenvolvimento, para a construção de uma política de Estado sob forte coordenação federativa do Ministério da Saúde (MS) e cujo orçamento é um dos maiores da União, apesar dos problemas de subfinanciamento público. A estrutura do aparato estatal responsável pela formulação e coordenação da política brasileira, embora ainda precária até 2005, quando apenas um terço do quadro administrativo era composto por servidores de carreira, se alterou a partir de 2011 pelo aumento de servidores e concursos públicos, passando a corresponder a $57 \%$ da força de trabalho lotada na sede do MS - segunda maior depois da educação (Costa; Neves, 2013).

Apesar de o CNS ser o canal por meio do qual a participação social se consolidaria como importante na definição da política, vale lembrar que o processo de institucionalização da política e da participação não é linear e, na saúde, foi afetado pelos limites estruturais e organizacionais da política pública, pela reelaboração da própria comunidade de política e pela agência recíproca dos atores com visões distintas, aspectos que influenciarão o processo atual de resiliência.

Em primeiro lugar, ao longo dos anos, é possível perceber o trabalho institucional dos atores sociais para que o CNS se mantivesse e consolidasse como espaço de participação e influência na política pública, especialmente por meio da estratégia de layering - pequenas 
modificações no seu desenho institucional que ao longo do tempo terão efeito importante na representatividade (Mahoney; Thelen, 2010, p. 16). Nesse sentido, houve o aumento gradativo do número de membros do conselho, de 24 para 48 (com duas suplências para cada vaga), e a escolha dos seus membros e do presidente passou a ser feita por meio de processo eleitoral - antes de 2006 o Ministro era diretamente seu presidente. A mudança mais importante na composição interna refere-se ao gradativo aumento da comunidade de política dos profissionais de saúde, de 4 para 12, e a inclusão no segmento dos usuários de categorias relacionadas às desigualdades decorrentes da raça, etnia, gênero, orientação sexual, preferência religiosa e portadores de determinadas patologias ou deficiências, de 5 para 13 representantes, ampliando também o número de representantes de associações comunitárias, movimentos sociais e ONGs, desde 2006 (Côrtes, 2009).

Essas mudanças refletem tanto as alterações no interior do MS durante os governos petistas, com inclusão de políticas de saúde para minorias, quanto a reformulação na comunidade de política e divisão no interior do movimento sanitário, entre categorias de médicos e não médicos, os primeiros juntamente com os prestadores de serviços que perdem espaço no Conselho. Porém, é preciso considerar que enquanto a representação da sociedade civil se fortalecia internamente e os atores lutavam pela manutenção e aprimoramento do papel do CNS no ciclo da política, outros atores estavam reciprocamente disputando influência. A disputa se dava ainda em termos desiguais, devido à sobreposição de competências e confusão de papeis nas diversas arenas setoriais da política, que permitem aos atores, com distintos recursos, navegarem por outras arenas com poder sobre a política. Uma das disputas se dá entre o Conselho Nacional de Saúde (CNS) e as Comissões Intergestoras Tripartites (CITs) e as Comissões Intergestoras Bipartites (CIBs). Criadas para discutir a implementação do
SUS, essas comissões ganham força crescente na medida em que passam a discutir questões relativas ao financiamento e à descentralização e coordenação federativa da estrutura gestora, e são importantes espaços de interação da burocracia com as unidades subnacionais, enquanto o CNS discute a natureza da política (Côrtes, 2009). Tanto os representantes da CIT quanto alguns entrevistados apontam para a inexistência de uma relação orgânica entre a Comissão e o CNS, seja porque muitas matérias não vão à deliberação do Conselho, ou porque o próprio conselho deixou de buscar a CIT por discordar dos pontos de pauta (Costa; Neves, 2013; Entrevistas 7, 9 e 10 - CNS).

Em segundo lugar, a reorganização da comunidade de política permitiu aos setores sociais se fortalecerem internamente, ao mesmo tempo que afastou gestores e prestadores privados do CNS e priorizou uma comunidade de política de não médicos em sua composição. Durante um regime com coalização governamental favorável à participação, especialmente os anos do PT no governo federal, o estudo do processo deliberativo mostra que, apesar dos embates, havia sinergia entre conselheiros da sociedade civil e representantes do governo, que algumas vezes se colocavam contra os atores do mercado (Silva et al., 2009). Ainda assim, a disputa pela influência do conselho nos rumos da política e pelo aprofundamento dos princípios do SUS era constante:

Nós passamos os doze anos, quase quinze, de governos progressistas, tentando interlocução na saúde, tentando ser recebidos pelos presidentes e mostrar o descaminho que o SUS tava assumindo, mas foi absolutamente em vão. [...] O espaço de intervenção da esquerda estava bem delimitado, [...] tinha grupos associados ao Sírio Libanês, Bradesco Seguros que tinham linha aberta de diálogo com a presidenta e presidente. (Entrevista 16 - CNS).

Apesar de discutirem temas diversificados, os debates relativos ao funcionamento do próprio conselho e às políticas e programas 
específicos que seriam implementados ocupavam grande espaço na agenda do conselho (50\% do tempo de discussões), em detrimento de discussões macro, organizadoras do SUS (Silva et al., 2009; Costa e Vieira, 2013). Além disso, os autores apontam o reduzido tempo dispensado para questões relacionadas às condições de trabalho dos profissionais da saúde, à gestão da saúde e às questões financeiras. Embora a articulação entre atores sociais e trabalhadores fosse sólida, e estes sejam os atores mais participativos por meio de falas, proposições e críticas durante as reuniões, os autores ressaltam que a capacidade de influírem nos centros de decisão e execução da política era dependente da forma na qual os gestores federais se posicionavam em relação ao fórum. Outros limites referem-se ao maior poder de fala de alguns atores, que afetam a democracia interna, e a diferenciação de conhecimento entre os representantes: “a representação ou é essencialmente técnica - se elegem porque sabem mais do SUS; ou o representante é completamente cru e vai ali fazer demandas pontuais, focalizadas a partir de sua base" (Entrevista 16 - CNS).

As causas apontadas para as dificuldades de influência da sociedade civil sobre a política, em geral, são múltiplas e não se devem apenas às mudanças na comunidade de política ou limites na representação. É preciso $\therefore$ adicionar como terceiro fator, os problemas de financiamento, que contribuíram para desafiar constantemente a participação. Segundo Cohn (2005), ao mesmo tempo que a Lei n. ${ }^{\circ}$ 8.142/90 serviu de incentivo à participação social ao vincular a criação de conselhos como condição de repasse de recursos, a participação social pode se reduzir a um debate sobre distribuição dos recursos e controle de sua implementação pelo Executivo, muitas vezes sem estabelecer diálogo com o governo no que tange aos rumos da política. Um dos efeitos sobre os atores sociais é que a participação teria se tornado um fim em si mesma, uma vez que a comunidade de política voltou-se essen- cialmente à ação nos conselhos, atuação nos processos de gestão no Executivo e formação de pessoas nas Universidades, abandonando outras práticas que foram comuns no período da redemocratização, como a disputa política do SUS no Legislativo e na esfera pública (Costa;Vieira, 2013)."Vamos a audiências públicas porque somos especialistas no tema, mas não é mais aquela ação permanente de quem incide sobre a política” (Entrevista 16 - CNS).

Em quarto lugar, e ligado aos limites da disputa por financiamento, é importante lembrar que a disputa de espaço dos atores dos movimentos se dá concomitantemente à forte agência do setor privado. A consolidação da estrutura organizacional do setor de saúde, a partir de sua característica dual e conflitante, público e privada, pauta uma atuação estatal diferenciada: o Estado é provedor e responsável pela regulação do mercado, garantindo concorrência, ampla oferta e direitos do consumidor (Menicucci, 2011). Ademais, nem o governo Dilma, nem Lula, apresentaram diferenças em relação aos governos FHC no que tange ao subfinanciamento (Soares e Santos, 2014). A luta em torno do financiamento e a manutenção da dualidade público e privado marcaram vários regimes:

Nunca a pauta da saúde foi dada facilmente. Os
Governos Dilma e Lula não resolveram a questão
do financiamento da saúde [...] em termos gerais,
independente de política partidária os governos têm
tido pouca preocupação com o modelo de saúde que
a gente quer. (Entrevista 2 - CNS)

A combinação entre fatores relacionais e organizacionais aponta para uma força relativa do CNS. Internamente, a comunidade se mostra forte e o CNS um local de disputa e debates, inclusive com recursos financeiros e capacidade administrativa maior do que outras IPs no nível federal. De outro lado, externamente, seu poder em relação a outras arenas setoriais e atores privados é muito reduzido, o que acaba afetando a capacidade de influência dos atores sociais a partir do Conselho. Com a alteração radical da coalizão governamental e, 
consequentemente, dos atores gestores do subsistema, espera-se que as interações socioestatais sejam remodeladas, bem como as práticas dos atores sociais que podem ou não ser direcionadas à preservação.

Desde o impeachment da presidenta, o Ministério da Saúde tem passado por uma profunda reestruturação e importantes decisões na política de saúde foram tomadas sem a deliberação do CNS, como a modificação na Política Nacional de Atenção Básica na Política de Saúde Mental e o corte no orçamento a partir da Emenda Constitucional N. 95. O processo deliberativo do conselho se alterou de maneira drástica e as reuniões ordinárias que ocorreram ao longo de 2017 e 2018 adotaram uma dinâmica completamente antagonista entre governo e atores sociais, os quais chamam atores governamentais de golpistas. Para um conselheiro, "a gente vê uma total tentativa de desmonte do SUS [...] a gente tá apagando um incêndio por dia" (Entrevista 1 - CNS). Não obstante esses revezes e a luta constante pela manutenção, pode-se afirmar que a institucionalização permite o CNS se proteger das contingências da política (Gurza Lavalle et al., 2019). Neste momento, tem feito diferença o desenho institucional do CNS e também a capacidade de articulação do movimento e da rede construída em torno de atores políticos e partidos. Vale lembrar que também as organizações e movimentos que militam em torno do tema não colocam em questão a legitimidade de atuar no Estado - tensão presente no movimento feminista como se verá na sequência. Na luta pela preservação do CNS, os atores estão adpatando suas práticas, tanto por meio da retomada ou intensificação de estratégias historicamente experimentadas, quanto pela atualização e adaptação das práticas e repertórios.

Primeiramente, há uma movimentação interna no CNS, que desde 2016 vem adotando notas públicas, manifestando posição diante de diversos projetos legislativos - dentre eles emendas à constituição (PEC), projetos de lei (PL) ${ }^{15}$ e medidas provisórias (MP 664 e $665)^{16}$; publicando moções de repúdio aos PLs e PECs que atingem à saúde; redigindo minutas de recomendação ao congresso e ao presidente da república, cartas de apoio a ações de movimentos sociais e de outros conselhos, ou Projetos de Lei e manifestos em defesa do SUS. Embora sejam medidas já adotadas na estrutura organizativa deste conselho, a análise qualitativa revela uma mudança a partir dos mandatos de Dilma Rousseff: torna-se claro o maior apoio ao Ministerio da Saúde e suas medidas durante os mandatos de Lula da Silva, e a intensificação do descontentamento com a política de saúde e a política em geral, após $2016^{17}$. Nos anos da presidenta, o maior número de moções chegou a 17 por ano (2013), após o impeachment, em 2017 e 2018, o CNS emitiu 27 e 24 moções, respectivamente. As recomendações que não ultrapassaram a média de 15, nos governos Lula e Dilma ${ }^{18}$, chegaram em 2017, 2018 e 2019 a 69, 65 e 56 respectivamente. Vale ainda destacar uma mudança de tom nas moções, uma vez que até 2011, se expressava a discordância com algumas medidas, sem usar necessariamente a palavra repúdio. A partir de 2015 há moções de repúdio ao governo federal e ao próprio presidente Temer, inclusive, em casos não relacionados à saúde. A mudança de postura se reflete no maior enfrentamento e pode também ser vista na $16^{\mathrm{a}}$

15 PEC 358 - Projeto de Emenda Constitucional, PEC do orçamento impositivo, torna obrigatória a execução das emendas parlamentares. Altera a metodologia de financiamento do SUS, reduzindo o montante de recursos federais destinado à saúde. PEC 451, que obriga os empregadores a garantirem, aos seus empregados, servicos de assistência à saúde, exceto os trabalhadores domésticos. E ao PL $4330 / 2004$, que regulamenta o trabalho terceirizado, permite a terceirização de qualquer setor de uma empresa, além de ampliar os tipos de empresas que podem atuar neste ramo.

16 Propõe alterações nos benefícios de pensão por morte e auxílio-doença e trata sobre o abono salarial e o seguro-desemprego, respectivamente

17 Do total de 162 moções emitidas em 17 anos (20032019), 52 ou $32.1 \%$ foram emitidas em 3 anos.

18 Com exceção do ano de 2008 que apresentou 50 recomendações. 
Conferência Nacional de Saúde, realizada em agosto de 2019. Com o lema " $8^{\mathrm{a}}+8$ Saúde é Democracia”, numa clara ação iterativa que contextualiza o passado, ao mesmo tempo que é projetiva, olhando para o futuro (Battilana e D'Aunno, 2009); os conselheiros relembram a histórica VIII Conferência e reclamam os direitos ainda não conquistados, associando a saúde à democracia. O documento orientador da Conferência trata da retomada de direitos definidos na Constituição de 1988 e propõe reformas como a tributária que defende cobrança de impostos sobre grandes fortunas adotando uma narrativa mais ampla sobre os problemas que afligem a área.

Segundo, diante da falta de compartilhamento de projetos políticos com as coalizões governamentais desde o impeachment, o CNS se vê agora na posição de retomada da defesa radical dos princípios do SUS e de práticas de ativismo em alguns setores, de maneira a influenciar a opinião pública e, quiçá, (re) politizar a questão da saúde como direito. A crise política tem levado à reflexão sobre o relacionamento do conselho com o público (Entrevistas 9 e 11 - CNS) e a aproximação com a sociedade se dá, especialmente, por duas frentes: inovação tática nas formas de comunicação com a sociedade e retomada do repertório de protestos que têm em comum o reforço da narrativa pública de defesa do SUS e a tenta- tiva de conquistar novas audiências frente ao percebido insulamento anterior.

O CNS vem utilizando de uma maneira mais intensa as plataformas de mídias sociais e tecnologias de informação e comunicação (Facebook, Youtube, Twitter e um Blog) desde 2012, além de atualmente transmitir ao vivo suas reuniões. Desde julho de 2015 o uso da Página do Facebook se intensificou, passando de 26.245 seguidores para 82.000 em janeiro de 2019. De julho de 2015 até outubro de 2018 o CNS realizou 2,546 postagens na sua Fan Page do Facebook, as quais informam sobre as atividades do Conselho (22,9\% do total de publicações) e sobre temas diretamente relacio- nados à crise e ao posicionamento político do CNS: riscos da perda de direitos e defesa do SUS $(8,9 \%)$, chamadas para mobilização pública e críticas ao governo (9,1\%), e informações sobre o engajamento do CNS com o legislativo e judiciário $(1,7 \%)^{19}$. Embora a estratégia digital só seja possível pela disponibilidade de recursos financeiros e humanos - equipe de quatro jornalistas com experiência em mídias digitais - as entrevistas realizadas com dois administradores da página e análise das atas revelam que a mesa diretora do conselho vem orientando a tomada de postura política da IP via redes sociais, chamando os conselheiros para compartilharem publicações e hashtags específicas em defesa do SUS, e intensificando o número de publicações a partir de 2015 (Almeida, 2020).

Vale destacar a inovação e adaptação criativa em relação à participação em protestos que não constavam do repertório de ação coletiva dos movimentos da saúde nos anos pós-redemocratização, além de ser incomum e, portanto, singular, que protestos sejam convocados a partir de uma instância de participação institucionalizada. As mobilizações mais relevantes que ocorreram no período foram: o ato político no primeiro dia da Conferência Nacional de Saúde (dezembro de 2015) - que reuniu 10 mil pessoas em frente ao Congresso - e os atos que se seguiram a partir da posse de Michel Temer: a Campanha São João, de Luta em Defesa do SUS, em todo o país (junho de 2016); a $2^{\text {a }}$ Marcha em Defesa do SUS e da Democracia, também, em direção ao Congresso (julho de 2016); o ato "+ direitos - depressão”, contra as Reformas da Previdência e Trabalhista, ocorrido em abril de 2017, na estação ro-

19 Resultado a partir da análise de conteúdo dos 2.546 posts extraídos da Fan Page do CNS, por meio de plataforma Netivzz. As demais publicações são sobre informações sobre política e recursos $(11,5 \%)$, informações sobre outras IPs (16\%), divulgação de eventos e campanhas (17\%) e atividades relativas à interação na Fan Page como curtir páginas $(12,1 \%)$. Vale ressaltar que a comparação com outro conselho de política revelou que apenas o CNS usava a Página para posicionamento crítico a respeito da política e do governo, bem como para chamada para manifestações da população. 
doviária de Brasília, e a Marcha Nacional da Saúde em abril de 2018 em várias capitais. Na reunião do CNS deslocada para a rodoviária de Brasília em abril de 2017, foi relançada a Frente em Defesa do SUS (ABRASUS) - lançada em 2015 - que reúne Conselhos de Saúde, entidades representativas, movimentos sociais, parlamentares, gestores e a sociedade civil. Além disso, o documento orientador da Conferência Nacional chamava os participantes para integrarem vários protestos em enfrentamento ao projeto conservador e ultraliberal, entre eles, Marcha das Margaridas; Dia Nacional de mobilização pela Educação; Grito dos Excluídos; Marcha das Mulheres Indígenas; Ato junto ao Congresso Nacional pela revogação da EC 95; Ato junto ao STF pela inconstitucionalidade da EC 95 e "Saúde não é mercadoria!".

Terceiro, percebe-se a mudança de postura em relação às arenas institucionais ao deixar de priorizar o Executivo, e o espaço próprio do conselho como arena exclusiva de luta, para intensificar a histórica interação do movimento sanitarista com o Legislativo alem de inovar na interação com o Judiciário. É possível ver a intensificação do lobby junto ao Poder Legislativo em vários momentos das atas, por exemplo, para coleta de assinaturas de 1,9 milhão de eleitores para a proposta de iniciativa popular - Projeto Saúde +10 (PLP $321 / 2013)$, que destina $10 \%$ da receita bruta da União para saúde, e para "frear" as mudanças na Política de Atenção Básica ${ }^{20}$. Além disso, a participação em audiências públicas é intensificada, até parte da $286^{\text {a }}$ Reunião Ordinária, em outubro de 2016, ocorreu no Plenário da Câmara dos Deputados para discussão da PEC 241 sobre o regime fiscal. É difícil ainda avaliar em que medida houve mudança de pos-

20 Publicada por meio de Portaria do MS, nº 2.436/2017, entre as polêmicas do novo texto da Política estão a retirada da obrigatoriedade de um número de agentes comunitários de saúde (ACS) nas Equipes de Saúde da Família e flexibilizacão das equipes de atenção básica, que podem ser criadas fora da estratégia da saúde da família (ESF). Concomitantemente, a mobilização dos ACS na regulamentação e aprovação da Lei $N^{\circ} 6.437 / 16$, que regula suas atividades, conseguiu garantir a presença dos agentes nas ESF e as atribuições distintas das categorias profissionais. tura efetiva em relação ao Legislativo, já que os conselheiros reconhecem, de um lado, que o momento de maior aproximação do movimento sanitarista com o Congresso se deu na Constituinte e, de outro, que apesar do contato menos intenso, em vários momentos o CNS se posicionou em relação a projetos legislativos e à posição de deputados, especialmente na luta pelo financiamento (Entrevista 6 e16 - CNS). De qualquer maneira, os conselheiros afirmam que esta estratégia é intensificada quando as portas do Executivo se fecham.

Por fim, o CNS vem acionando a justiça para fazer valer seu direito de instância máxima de deliberação. Juntamente com a Frente pelo SUS, o CNS tem atuado em apoio às duas Ações Diretas de Inconstitucionalidade (ADI5633 e ADI-5658) que tramitam no Supremo Tribunal Federal (STF), e questionam a constitucionalidade de dispositivos da EC 95/2016. Entrevistados relatam ainda a aproximação com membros do Ministério Público que os têm orientado em relação às ações judiciais (Entrevistas 6, 9 e 14 - CNS). Quando questionados sobre a forma de atuação do conselho e de suas organizações pós impeachment para se defender das ameaças, também incluem: uso de rádio e mídias alternativas, ocupação de cargos na burocracia, organização de congressos e encontros, conexão com a base, interação com Executivo e universidades, lobby nos espaços legislativos municipais, moções e manifestos, petições, participação em outras instituições, coleta de assinaturas para iniciativas populares, protestos e marchas, audiências públicas no Parlamento e uso da mídia em geral. Em todos estes casos o CNS se adapta e preserva seu papel de articulador do movimento e lócus de construção das estratégias de interação socioestatais, em um claro processo de resiliência.

\section{O OCASO DO CONSELHO NACIO- NAL DOS DIREITOS DA MULHER}


A comparação da análise anterior com o Conselho Nacional de Direitos da Mulher (CNDM) ajuda a visualizar um ambiente distinto, tanto em relação às práticas adotadas pelos atores em um momento adverso, quanto às condições sob as quais esta agência se desenvolve. Diferentemente do CNS, trata-se, pelo menos momentâneamente, do ocaso da participação institucional em termos de diminuição do poder e da importância do CNDM para a política de gênero. A atenção ao processo de construção da participação institucional nesse caso ajudará a compreender as dificuldades dos atores sociais absorverem a oposição que, embora sempre presente, se intensifica nos tempos de impeachment, e se adaptarem a fim de preservar o conselho como espaço de deliberação.

Em primeiro lugar, a relação do movimento feminista com os atores políticos também é intensa, porém, menos articulada, do ponto de vista da capacidade de inserção na burocracia estatal, do estabelecimento da questão de gênero como política pública e da opção pela via participativa no interior do Estado. No que tange à interação socio-estatal, o debate da autonomia versus atuação nas instituições políticas sempre foi central, diante da pluralidade e heterogeneidade do movimento nas suas tensões com o racismo e a questão de classe (Alvarez, 2014). A partir das décadas de 1980 e 90, o pluralismo fica mais contundente pelo crescimento das articulações entre feministas e partidos, governos e universidades, e transversalização da questão de gênero para as instituições políticas. Nesse processo, o PT foi ator fundamental para ampliar e impulsionar o campo feminista, aliando trajetórias políticas de ativistas feministas com o partido e movimentos sociais.

Anteriormente, a opção pela via participativa nos conselhos também não era valorizada pelo movimento feminista entendido em seu singular. Contudo, a chegada de coalizões governantes nos estados, opositoras ao regime militar, como Franco Montoro em São Paulo,
Tancredo Neves em Minas Gerais e Leonel Brizola no Rio de Janeiro, e de experiências estaduais de participação, impulsionou o movimento a propor um Conselho Nacional em 1985, a partir de negociação direta com o então candidato à presidência, Tancredo Neves. A história alterou os fatos mas a chegada de José Sarney à presidencia manteve a promessa e o CNDM foi criado por meio de lei, o que garantiu sua permanência ao longo de todos estes anos, embora, não necessariamente o seu pleno funcionamento, passando a ocupar uma posição de Secretaria no Ministério da Justiça com funcionários, autonomia financeira e administrativa. A partir daí, o CNDM foi importante lócus de discussão do movimento durante a Constituinte e, para além dela, estabelecendo-se no interior do Estado um espaço de aglutinação das demandas do movimento e visibilidade do campo discursivo de gênero (Alvarez, 2014). Ademais, destaca-se o "lobby do batom", como era chamado pelo próprio CNDM, com ganhos importantes na Constituinte, como direitos trabalhistas, licença maternidade e paternidade e 44 horas de jornada de trabalho. Vale lembrar que apesar desta comunidade de política conquistar um espaço institucional, até então não se transformara em lócus duradouro de formulação de políticas de gênero no Estado. No governo de Fernando Collor, o CNDM perdeu sua autonomia administrativa e financeira e diante do enfraquecimento e perda de diálogo, as feministas se afastaram pela primeira vez do espaço (Macaulay, 2010; Pinheiro, 2015).

A esse respeito, vale destacar que durante os anos 1990 a institucionalização do movimento feminista no Estado passa ao largo do CNDM, e o movimento é fortalecido e diversificado por suas articulações com o movimento latino-americano e também nas conferências internacionais. A relação com o Executivo se deu via absorção das questões de gênero pela agenda neoliberal anti-pobreza e pela profissionalização do feminismo a partir de ONGs. Essas parcerias contribuíram para situar as 
mulheres como formuladoras de políticas públicas (Alvarez, 1999), mas sem que o Estado assumisse a centralidade, já que eram financiadas especialmente por agências de cooperação internacional. Embora as ONGs tenham se tornado dominantes no campo feminista, ocorria paralelamente a pluralização e diversificação do movimento por meio da advocacy em instituições governamentais, especialmente, com a participação na formulação de políticas públicas nos estados, e órgãos não governamentais; e desenvolvimento de redes, comunidades e identidades centradas no movimento, atuação em distintos movimentos e instituições como movimento estudantil, étnico-raciais, sindicatos e partidos (Pinheiro, 2015; Alvarez, 2014). As idas e vindas do movimento a depender do regime mostram, porém, que até 2003 , não havia se configurado um subsistema de políticas públicas de gênero. Nas palavras de uma entrevistada (CNDM 9), "éramos dependentes do humor do presidente”.

A proximidade do movimento com o Partido dos Trabalhadores, inclusive, por meio da filiação ao partido, foi fundamental para a reorientação do governo federal e institucionalização das políticas de gênero. O passo mais importante foi a criação da Secretaria Especial de Políticas para Mulheres (SPM) com status de ministério a partir de 2003, o que ampliou o financiamento estatal de projetos das ONGs e outros entes federativos e contribuiu para a instituição de órgãos de políticas para mulheres nos estados e municípios. De acordo com dados da SPM (2016), existiam pelo menos 795 organismos nos 26 estados e no Distrito Federal. Pela primeira vez, o Plano Plurianual (2004-2007) inseriu como plataforma de governo "a viabilização da inclusão social, da equalização das oportunidades - gênero, raça, etnia, pessoas portadoras de necessidades especiais e da cidadania” (Bandeira, 2005, p. 3). Basta lembrar que o "carro-chefe" dos programas de inclusão do governo federal, o Bolsa Família, teve impacto no empoderamento e melhoria da saúde das mulheres ao legitimá- -las como representantes das famílias (Leroy, Ferreira e Silva, 2011).

A instituição da SPM impactou o desenho do Conselho Nacional que, pela primeira vez, passou a ter uma composição similar a outras instâncias de controle social, retornando à influência do movimento feminista. Assim como o CNS, a estratégia de mudança envolveu a introdução de novas regras à estrutura existente, e a entrada de atores que não tinham acesso às instituições. Em comparação, antes de 2003 as conselheiras eram indicadas pela presidência da república, sem consulta à sociedade civil e, na ausência de recursos e funcionalidade, deixou de ser um espaço importante de interlocução do movimento feminista. A partir da eleição de Lula, o Conselho passou por sucessivas mudanças na sua composição e funcionalidade, instituindo um novo desenho institucional, responsável por diversificar os interesses representados do movimento feminista, como também seu escopo de deliberação, mas sem retomar sua autonomia financeira e administrativa. Houve aumento considerável no número de representantes da sociedade civil - que ocupa $60 \%$ dos assentos, os quais são escolhidos a partir de processo eleitoral público. O CNDM é composto por 41 membros, 21 representantes da sociedade civil eleitos, três mulheres com notório saber em política de gênero - indicadas pela Ministra e movimentos sociais - uma conselheira emérita e 16 gestores. Com estas alterações, houve a inclusão no Conselho de redes e ONGs feministas com base popular como a Articulação de Mulheres Brasileiras/AMB, Articulação de Organizações de Mulheres Negras Brasileiras/AMNB, a Marcha Mundial das Mulheres/MMM, a Rede Mulher e Mídia/RMM ou Intervozes, as mesmas que depois renunciariam a seus assentos com o início do impeachment.

Ao contrário do CNS, o CNDM não controlava um fundo financeiro específico para mulheres, o que o torna dependente da SPM e de suas articulações com outros órgãos de governo. Ademais, as pautas das reuniões geral- 
mente eram apresentadas pela SPM, enquanto as conselheiras da sociedade civil expressavam opiniões, numa relação mais de parceria. Tal dependência e fragilidade administrativa prejudicavam o seu papel na formulação de políticas públicas, levando a uma baixa capacidade propositiva e deliberativa, e dificuldades de produzir decisões vinculantes no sentido de gerar obrigatoriedade do governo (Araújo, 2014). Nos níveis subnacionais, a presença de Conselhos de Direitos das Mulheres ainda é baixa (aproximadamente 15\% dos municípios), uma vez que não são requeridos por lei federal e dependem das características políticas locais, como organização da sociedade civil e coalizão governamental (Romão, Gurza Lavalle e Zaremberg, 2017).

À fragilidade do CNDM é preciso adicionar o fato de que a capacidade estatal da SPM para pautar a política era muito reduzida em termos de recursos e pessoal - especialmente cargos comissionados e incorporação de mulheres ativistas ${ }^{21}$. Ao mesmo tempo, dado o caráter transversal da política e limites no orçamento, a Secretaria era dependente do estabelecimento de parcerias com outros ministérios - questionando a ideia de que existem áreas neutras em relação à condição de gênero - e dos convênios realizados com entidades civis sem fins lucrativos e entes federativos. Nesse período, uma diversidade de iniciativas encon$\therefore$ trou apoio, mas os projetos voltados ao campo de violência contra as mulheres e ao acesso ao mercado de trabalho mantiveram centralidade (Pinheiro, 2015). Embora tenham ajudado a construir uma agenda política no governo federal, a falta de autonomia administrativa e financeira da SPM não levou à consolidação dos direitos das mulheres na estrutura do Estado, especialmente, do ponto de vista de estabelecer coalizões que apoiem mudanças reais nas leis e na implementação de políticas públicas.

21 Algumas feministas adentraram o Estado por meio de concursos públicos ou chamadas por tempo determinado em agências estatais fora da SPM, o que ajudou nas parcerias com outros ministérios, como saúde e desenvolvimento agrário (Pinheiro, 2015, p. 180).
Além disso, vale destacar que em relação ao dilema de agenda-setting, a política de direitos para mulheres conseguiu ampliar a visibilidade e atenção agendar problemas, mesmo com fortes disputas no seu interior e na sociedade.

Persistia o dilema de que era preciso resistir aos movimentos contrários à institucionalização das questões de gênero no interior do Estado, o que dificultava as parcerias com outros ministérios e órgãos. As resistências contra as políticas de gênero se intensificaram na eleição de 2010 (com Dilma Rousseff), mas já estavam presentes anteriormente (governo Lula), haja vista a ampla coalizão com setores conservadores como evangélicos e bancada ruralista. Por exemplo, quando na II Conferência Nacional de Políticas para Mulheres, em 2007, é retirada a proposta de legalização do aborto, diante da mobilização de entidades religiosas da igreja católica, "veio um recado do Planalto que era para recuar, que Lula não ia assumir, e que a gente tinha que trabalhar para não sair isso da Conferência. Coube a mim defender esta posição enquanto governo [...] Ficamos quase submetidos a uma obediência forçada de cala boca" (Entrevista 16 CNS/CNDM). Outras iniciativas neste campo, como a Comissão Tripartite, instituída em 2005, envolvendo Executivo, Legislativo e sociedade civil para revisão da lei do aborto, teve sua proposta rejeitada em 2008. O crescimento do projeto político conservador nas elites políticas e na sociedade, por meio da reação negativa à legitimidade da agenda de gênero e diversidade sexual em projetos apresentados no Congresso, mostra as dificuldades políticas e socioculturais de implantação de uma política para mulheres (Miskolci, Campana, 2017).

Além disso, os conflitos também se davam no próprio movimento, diante da discordância com a atuação por dentro do Estado ou das ações da SPM. Por vezes, essa pluralidade se expressava nas Conferências, onde a disputa pela representatividade era muito acirrada, além de denunciarem os limites das políticas estatais implementadas (Ramos e Faria, 2013). 
Desse modo, se para o CNS o problema foi a despolitização da participação em relação ao seu âmbito externo (governo e esfera pública), no CNDM havia uma despolitização interna, como mostram as entrevistas:

O CNDM tem uma característica de muita sororidade, muito pouco crítica, muito mais um conselho propositivo e operativo do que efetivamente um conselho de debate crítico e de uma interposição proativa nas políticas. Eu acho que carrega um pouco a história do próprio feminismo. É quase como se aquilo fosse um bem, uma conquista e que devesse ser preservado. [...] Tem o problema de ser um Conselho que não tem uma política de intervenção, ele incide sobre conjunto de políticas que interessam às mulheres. Um debate sobre política econômica não tem lugar no CNDM e é tão impactante sobre a vida das mulheres. Ou sobre um processo legislativo que tenha a ver com as mulheres, isso também é vazio ali dentro (Entrevista 16 - CNS/CNDM).

Mas ali imperava, muito mais do que na saúde, uma prática de, vou dizer uma palavra forte, de cooptação. É como [se] uma visão crítica incomodasse, porque a crítica a um governo incomodava. Erro principal do lulismo foi esta forma de desarticular, despolitizar os movimentos sociais, sindicatos e todos os campos organizativos da sociedade [...] Dilma ousou um pouco mais, em dar um aspecto mais operativo a SPM na questão da violência, mas por outro lado ela fechou com toda segurança, as portas e janelas, para uma negociação com congresso ou com próprio movimento social (Entrevista 16 - CNS/ CNDM).

Como estavam ali na SPM pessoas conhecidas, com quem você fez sua militância e lutou ao seu lado, ela vai virar uma gestora, esse monitoramento, essa crítica existe com um cuidado bem redobrado. Este cuidado é desde que o Lula chegou. (Entrevista 1 CNDM).

O CNDM então funcionava como espaço de controle social limitado pelo seu próprio desenho e pelos constrangimentos políticos, administrativos e financeiros da SPM, ao mesmo tempo que participava de um esforço coletivo de introdução de uma pauta inclusiva em relação aos direitos das mulheres. As ativistas relatam esta dupla faceta de estar em um go- verno aliado, que trouxe vários ganhos para a agenda de gênero e formulação de políticas públicas, mas sem que temas centrais para o movimento, especialmente sobre direitos sexuais e reprodutivos, tivessem espaço. Apesar dos limites, o espaço de interlocução existia. O impeachment representou o crescimento de forças de oposição e conservadoras que já se impunham nos governos anteriores.

Diante deste cenário, sete representantes de redes e movimentos feministas avaliaram que, pela segunda vez, não fazia mais sentido o esforço de se manter neste espaço: "nós passamos pelo menos uns três meses discutindo, que já estava naquele processo de impeachment. Nesse processo, todos nós já começamos a fazer as consultas internas e você tinha posições diferenciadas. A gente passou uns 3 meses para chegar a um consenso" (Entrevista 1 - CNDM). Além desta percepção da mudança, as participantes destacam como central a ideia de que era preciso reconstruir laços de solidariedade com o (s) movimento (s) e fortalecer a base - um outro tipo de trabalho institucional fora do Conselho. Neste caso, o Estado perde a centralidade da ação, embora continue como alvo de pressão dos movimentos. A estratégia de saída, no entanto, não foi consensual entre conselheiros. Apesar da baixa institucionalização, "o posicionamento (nome da instituição omitido) é de não retirada, porque considera que é o espaço conquistado pelo movimento social. Para nós, promover política implica também em resistência" (Entrevista 4 - CNDM). O uso do termo resistência, para a entrevistada, significa denunciar, mesmo que não seja ouvida pelo governo, e se opor às mudanças.

Mas não há evidências de que o CNDM tenha se tornado um espaço de resiliência, tal qual advogado aqui, como preservação de sua função e adaptação criativa, mas sim do seu ocaso, pois se manteve apenas formalmente. Durante o ano de 2017, o CNDM praticamente não se reuniu. Em várias visitas, não foi possível identificar como estava operando 
o Conselho, e obter informações das reuniões, ou mesmo cópia das atas. Em 2018, houve o processo eleitoral finalizado em julho e a última reunião ocorreu em outubro. Desde a posse do governo Bolsonaro, o Conselho aguardava a nomeação da nova Secretária, a qual ocorreu em maio de 2019. Vale lembrar as mudanças do novo governo: perda do status de Ministério (já no final do governo Dilma); reestruturação para fazer parte do Ministério da Mulher, da Família e dos Direitos Humanos; website (da agora Secretaria) reformulado e desatualizado; ausência de material disponibilizado online sobre as gestões anteriores ou atual que ajudem a entender atividades.

As mudanças institucionais introduzidas no CNDM de fortalecimento da sociedade civil sem a concomitante mudança do seu poder de deliberar sobre a política não foram suficientes para gerar um processo de manutenção e adaptação. Entretanto, não se deve descartar os ganhos, já que parecem alimentar outro tipo de resiliência dos movimentos que precisa ainda ser estudada. Diferentemente do Conselho de Saúde, não se trata de (re) politização da temática, pois, nos últimos anos o país vem experimentando a emergência de atores sociais e a pluralização do movimento, com surgimento de distintas correntes que colocam a igualdade de gênero como pauta central no debate público. Ao contrário dos que advogam a separac ção nas formas de ação entre os movimentos que foram para a máquina estatal e estas novas participantes, é importante ver as pontes entre estes dois processos, na medida em que a institucionalização da política pública para as mulheres no interior do Estado permitiu a geração de uma linguagem de direitos e o avanço em políticas públicas que impactam socialmente.

Os dois casos de políticas aqui abordados, mostram que, de um lado, temos uma política de saúde fortemente institucionalizada como resultado das interações socio-estatais e características da política pública, mas que carece de links mais diretos com a população; de outro, teríamos na política de direitos para as mulheres, maior possibilidade de oxigenação e pluralismo. Ao invés de inovação dos repertórios a partir do Conselho, as feministas voltam a um repertório do qual nunca se afastaram completamente, especialmente os protestos e organização da militância, mas, continuam híbridas, ou seja, apostando nos campos institucional e não-institucional (Alvarez, 2014). As estratégias citadas pelas entrevistadas representam um retorno do contato com o Legislativo, uso de redes sociais e da mídia, fortalecimento das marchas e protestos. O repertório das ruas, conforme as entrevistadas, é o momento em que ocorre a sinergia entre o "novo" e o "velho" feminismo, por exemplo, no Dia Internacional da Mulher, Marcha das Mulheres Negras e Marcha das Vadias (Entrevistas 1, 2, 8- CNDM; Schumaher, 2018). Enquanto dados de participantes da IV Conferência Nacional de Políticas para Mulheres de 2016, mostram que as Conferências pouco incorporam feministas jovens (9,3\% tinham menos de 30 anos), seja pela pouca disposição destas interagirem nestes processos institucionalizados, seja pelas dificuldades da escala e tempo livre necessário para participar (Marques, 2018).

Os dados apontam que há inovações de táticas, repertórios e atores no movimento feminista e que, nestes três anos analisados, não é possível ver a resiliência institucional do CNDM, o que não significa que ele não possa retornar com força em algum momento. Tal qual os teóricos dos movimentos sociais, as ativistas avaliam que é hora de mudar de estratégias:

As estratégias de atuação sempre mudam de acordo com o contexto. Elas são flexíveis. Mesmo porque as suas oportunidades aumentam ou diminuem, dependendo do contexto. Nós temos muito menos oportunidades agora. Então, conseguir um espaço em um jornal, fazer uma manifestação, desenvolver um projeto, é muito mais complicado. Por exemplo, fazer um diálogo com o Legislativo, que foi primoroso, independente do partido político, no processo Constituinte, isso se rompeu. Por outro lado, há uma porta aberta de diálogo com o Judiciário (Entrevista 3 - CNDM) 
Apesar da opinião positiva sobre o relacionamento com o Legislativo, as alianças entre o movimento e parlamentares na promoção de políticas para as mulheres foram mais pontuais, como a aprovação da Lei de Planejamento Familiar em 1996, e da Lei Maria da Penha (Entrevista 8 - CNDM). Apesar da recorrente sub-representação feminina, entre as mulheres que são fortemente engajadas no movimento feminista, as participantes das conferências nacionais, e mesmo as filiadas a partidos políticos, não há uma correspondente integração competitiva na concorrência eleitoral ${ }^{22}$ (Marques, 2018). Porém, a disputa nas eleições por meio de coletivos feministas, intensificada em 2018, parece ser uma nova tendência que precisa ser melhor investigada a fim de compreender em que medida alterarão a correlação de forças entre movimento feminista e arenas estatais. Finalmente, diante do fechamento de espaço de atuação na arena do Executivo, pesquisas começam a apontar também para uma aposta nas arenas do Judiciário, por exemplo, nas audiências públicas realizadas no STF diante da Arguição de Descumprimento de Preceito Fundamental, ADPF 442, sobre o aborto, ou em ações para se oporem à violência contra mulheres (Elias, 2018; Elias e Machado, 2017).

\section{CONSIDERAÇÕES FINAIS}

Os resultados acima apresentados confirmam as potencialidades do conceito de resiliência institucional defendido neste artigo, que leva em conta, para além da manutenção da instituição, o esforço e ação intencional dos atores para preservar suas funções e objetivos, bem como adaptar-se criativamente frente a um contexto de ameaças diretas de sua existência. O Conselho Nacional de Saúde pode ser considerado como um caso típico, que re-

22 Dados de Survey aplicado a 389 conferencistas da $4^{\mathrm{a}}$ Conferência Nacional, selecionadas aleatoriamente. úne várias possibilidades de resiliência quando comparado a outras IPs no nível nacional. A participação dos atores sociais vai além da institucionalidade do Conselho e alcança a política pública, de modo a incidir na construção das capacidades estatais no que tange ao modelo de formulação e implementação da política de saúde. Concomitantemente há um processo de institucionalização de um campo público e baseado em princípios universalistas do SUS, que alteram a forma em que o Estado brasileiro historicamente tratou a atenção à saúde, sem romper completamente com o legado público-privado. A mútua constituição entre movimento sanitário e atores estatais nos três níveis de governo ajudou a construir este pilar, fazendo com que fossem menos dependentes de regimes e coalizões governamentais diretamente favoráveis aos seus projetos. Contudo, o subsistema de políticas se modificou intensamente ao longo destes 30 anos, na medida em que os espaços de controle dos gestores paulatinamente se fortalecem e perdem a clara vinculação com o controle social.

Adicionando a força e agência do setor privado pode-se vislumbrar a disputa desigual em que está imerso o controle social. Nesse sentido, mesmo com as vantagens que reúne, as quais facilitam a agência, há fragilidades importantes que deixam em aberto a pergunta sobre a continuidade dessa resiliência. Ademais, os dados mostram que as condições institucionais e políticas do CNS não explicam sozinhas as práticas dos atores. Há um deliberado processo de esforço e busca por adaptar-se, como se percebe na intensificação de algumas práticas organizacionais, tentativa de retomada do diálogo com o Legislativo e com a sociedade, além da construção de canais de diálogo com atores do Ministério Público e do Judiciário para fazer valer seu papel no controle social da saúde, uma novidade que surge como resposta à conjuntura.

Por outro lado, esta fotografia instantânea dos últimos três anos permite afirmar o ocaso do CNDM, embora se mantenha formalmente. Assim como na saúde, o conselho é resultado 
das interações socioestatais, mas para os movimentos feministas, a vinculação a atores de esquerda e coalizões governamentais favoráveis teria sido central para a sua entrada no Estado, em 1985 e em 2003. Esta aliança estaria mais fortalecida durante os governos petistas devido à proximidade dos militantes, mas a partir de uma relação menos simbiótica. Na saúde, o conflito se dava: no interior de um mesmo campo de política, com a manutenção do poder deliberativo e o controle sobre a execução de programas e projetos. No CNDM, além de disputar influência com a própria SPM, estava imerso em uma estrutura com pouca autonomia financeira e administrativa, além de tentar influenciar decisões em outras áreas do governo, por exemplo, políticas e propostas em defesa dos direitos das mulheres que precisavam ser implementadas por outros ministérios e áreas, como segurança pública, desenvolvimento. É preciso ainda adicionar a natureza da própria política que nunca foi consolidada e passou a ser fortemente contestada, especialmente, a partir dos governos Rousseff, quando a aliança com setores evangélicos e conservadores começa a cobrar o seu preço. Embora o debate da saúde pública versus privada exista, os atores contrários ao modelo universal e público de saúde precisam disputar ideias defendidas até então por um campo consolidado. Todas estas condições adversas, porém, não representam $\dot{\hat{N}}$ um retrocesso na ideia de que instituições "fracas" possam ser resilientes.

Os dados mostram que houve ao mesmo tempo uma escolha deliberada por parte de alguns atores por não preservarem este espaço. A baixa institucionalização no interior do Estado, comparada ao movimento sanitarista, é de alguma maneira compensada com a pluralização e capilarização do movimento na esfera pública e politização da temática. Ao mesmo tempo a pluralização das demandas e vozes, num campo tão amplo e transversal, dificulta a coordenação e articulação de resiliências em torno de pautas comuns. "O movimento feminista tem muita cabeça, muita organização, é explodido"
(Entrevista 1, CNDM)

A realização de pesquisas comparativas em outras arenas contribuiria para saber se outros fatores ajudam a explicar resiliência. O Conselho Nacional dos Direitos Humanos, por exemplo, apresenta histórico distinto e desde o Decreto n. 9759/2019 tem buscado preservar seu espaço, inclusive, por meio de alianças com organismos internacionais. As condições de resiliência das IPs nos níveis locais e estaduais é outra agenda de pesquisa. Ainda é cedo para saber se os novos repertórios e estratégias que estão sendo adotados alterarão a capacidade da participação social de construir coletivamente as políticas públicas e quais serão os diferentes efeitos de cada um deles. Contudo, a institucionalização mais profunda no campo da saúde começa a mostrar alguns resultados. Em quais casos a experiência pretérita de interação com o Estado vai ajudar a construir resiliência institucional, ou gerar novos modelos de interação socioestatal, é uma pergunta coringa que se coloca para o campo da participação.

Recebido para publicação em 26 de agosto de 2019 Aceito em 17 de abril de 2020

\section{REFERÊNCIAS}

ABERS, R. Bureaucratic activism: pursuing environmentalism inside the Brazilian state. Latin American Politics and Society, v. 61, n. 2, p. 21-44, 2019.

ABERS, R.; ALMEIDA, D. Participação no século XXI: o embate entre projetos políticos nas instituições participativas federais. In: ARRETCHE, M.; MARQUES, E.; FARIA, C. A. P. (Orgs.). As políticas da política: desigualdades e inclusão nos governos do PSDB e PT. São Paulo: UNESP, 2019. p. 373-399.

ABERS, R.; KECK, M. E. Practical authority: agency and institutional change in Brazilian water politics. New York, Oxford: Oxford University Press, 2013.

ABERS, R.; SERAFIM, L.; TATAGIBA, L. Repertórios de interação estado-sociedade em um estado heterogêneo: a experiência na era Lula. Dados, v. 57, p. 325-357, 2014. 
ABERS, R.; SILVA, M.; TATAGIBA, L. Movimentos sociais e políticas públicas: repensando atores e oportunidades políticas. Lua Nova, 105, p. 15-46, 2018.

ADGER, W. N. Social and ecological resilience: Are they related? Progress in Human Geography, v. 24, n. 3, p. 347-364, 2000.

ALMEIDA, D. Civil society representation and digital accountability in Brazilian participatory institutions. Journal of Chinese Governance, [online], p. 1-29, 2020. https://doi.org/10.1080/238 12346.2020.1721956

;CUNHA, E. Brazilian Social Assistance policy: an empirical test of the Concept of Deliberative Systems. Critical Policy Studies, 10: 284-304, 2016.

ALVAREZ, S. Advocating feminism: the Latin American feminist NGO 'boom'. International Feminist Journal of Politics, v. 1, n. 2, p. 181-209, 1999.

.Para além da sociedade civil: reflexões sobre o campo feminista. Cadernos Pagu, v. 43, p. 13-56, 2014

ARAÚJO, M. G. Feminismo e o estado: relações possíveis a partir do Conselho Nacional dos Direitos da Mulher. 2014. 124 p. Dissertação (Mestrado em Ciência Política), Instituto de Ciência Política da Universidade de Brasília.

AVRITZER, L.; NAVARRO, Z. (Orgs.). A inovação democrática no Brasil: o orçamento participatvo. São Paulo: Cortez, 2003.

BANDEIRA, L. Fortalecimento da Secretaria Especial de Políticas para as Mulheres: avançar na transversalidade da perspectiva de gênero nas políticas públicas. Relatório de Pesquisa Convênio CEPAL/SPM, 2005.

BATTILANA, J.; D’AUNNO, T. Institutional work and the paradox of embedded agency. In: LAWRENCE, T. B.; SUDDABY, R.; LECA, B. (eds.). Institutional work: Actors and agency in institutional studies of organizations. Cambridge: Cambridge University Press, 2009, p. 31-58.

BERK, G.; GALVAN, D. C. Processes of creative syncretism: experiential origins of institutional order and change. In: BERK, G., GALVAN, D. C. \& HATTAM, V. (Orgs). Political creativity: reconfiguring order and change. Philadelphia: University of Philadelphia Press, 2013. p. 29-54.

COHN, A. O SUS e o direito à saúde: universalização e focalização nas políticas de saúde. In: LIMA, N. et al (Org.). Saúde e democracia: história e perspectivas do SUS. Rio de Janeiro: Fiocruz, 2005. p. 394-395.
COLLIER, R.; COLLIER, D. Shaping the political arena: critical junctures, the labor movement, and regime dynamics in Latin America. Notre Dame, University of Notre Dame Press, 2002. p. 27-39.

CÔRTES, S. M. V. Participação e saúde no Brasil. Rio de Janeiro: Editora Fiocruz, 2009.

COSTA, A. M.; VIEIRA, N. Participação e controle social na saúde. In: FUNDAÇÃO OSWALDO CRUZ - FIOCRUZ. A saúde no Brasil em 2030: prospecção estratégica do sistema de saúde brasileiro: organização e gestão do sistema de saúde [online]. Volume. 3. Rio de Janeiro: Fiocruz/Ipea/Ministério da Saúde/Secretaria de Assuntos Estratégicos da Presidência da República, 2013. p. 237-271.

COSTA, L. A.; NEVES, J. A. Burocracia e inserção social: um estudo sobre o Ministério da Saúde na gestão do Sistema Único de Saúde (SUS). Saúde e Sociedade, v. 22, n. 4, p. 1117-1131, 2013.

CRUZ, L. B. et al. Institutional resilience in extreme operating environments: the role of institutional work. Business and Society, v. 55, n. 7, p. 970-1016, 2016.

DAGNINO, E. Sociedade civil e espaços públicos no Brasil. In: (Org.). Sociedade Civil e Espaços Públicos no Brasil. São Paulo: Paz e Terra, 2002. p. 9-15.

DOWBOR, M. Escapando das incertezas do jogo eleitoral: a construção de encaixes e domínio de agência do movimento municipalista de saúde. In: GURZA LAVALLE, A. et al. (Orgs.). Movimentos sociais e institucionalização: políticas sociais, raça e gênero no Brasil pós-transição. Rio de Janeiro: EDUERJ, 2019. p. 89-118.

ELIAS, M. L. Democracia e aborto: uma reivindicação feminista em contexto de guinada conservadora no Brasil. Paper apresentado no Encontro Anual da ANPOCS, 2018.

;MACHADO, I. Fighting gender inequality: Brazilian feminist movements and judicialization as a political approach to oppose violence against women. American Society for Public Administration. Published Online, p. 1-16, 2017

ESCOREL, S. et al. As origens da reforma sanitária e do SUS. In: LIMA, N. et al. (Orgs.). Saúde e democracia: história e perspectivas do SUS. Rio de Janeiro: FIOCRUS, OPS/OMS, 2005. p. 59-81.

FALLETI, T. G. Infiltrating the State: The evolution of health care reforms in Brazil, 1964-1988. In: MAHONEY, J.; THELEN, K. (Orgs.). Explaining institutional change: ambiguity, agency and power. Cambridge, Cambridge University Press, 2010. p.38-62. 
FARIA, C. F. Sobre os determinantes das políticas participativas: a estrutura normativa e o desenho institucional dos conselhos municipais da saúde e de direitos da criança e do adolescente no Nordeste. In: AVRITZER, L. A participação social no Nordeste. Belo Horizonte: UFMG, 2007. p. 111-133.

GORDIN, J. P.; RENNO, L. Institutional innovation and the steering of conflicts in Latin America. United Kingdom: ECPR, 2017.

GURZA LAVALLE, A.; BARONE, L. S. Conselhos, associações e desigualdade. In: ARRETCHE, M. (Org.). Trajetórias das desigualdades: como o Brasil mudou nos últimos cinquenta anos. São Paulo: CEM, 2015. p. 51-78.

GURZA LAVALLE, A.et al. (Orgs.). Movimentos sociais e institucionalização: políticas sociais, raça e gênero no Brasil pós-transição. Rio de Janeiro: EDUERJ, 2019.

GURZA LAVALLE, A.; VOIGT, J.; SERAFIM, L.. O que fazem os conselhos e quando o fazem? Padrões decisórios e o debate dos efeitos das instituições participativas. DADOS - Revista de Ciências Sociais, Rio de Janeiro, v. 59, n. 3, p. 609-650, 2016.

HOLLINGS, C. S. Resilience and stability of ecological systems. Annual Review of Ecology and Systematics, v. 4, p. 2-23, 1973.

JOAS, H. The creativity of action. Chicago: University of Chicago Press, 1996.

KLEIN, R. J. T.; NICHOLLS, R. J.; THOMALLA, F. Resilience to natural hazards: how useful is this concept? Environmental Hazards, v. 5, n. 1, p. 3545, 2003.

LABRA, M. E. Associativismo no setor saúde brasileiro e organizações de interesse do empresariado médio. Phisis, Revista de Saúde Coletiva, Rio de Janeiro, v. 3, n. 2, p. 193-225, 1993.

ণิ LAWRENCE, T. B.; SUDDABY, R.; LECA, B. Introduction: theorizing and studying institutional work. In: (eds.). Institutional work: actors and agency in institutional studies of organizations. Cambridge: Cambridge University Press, 2009. p. $1-27$.

LEROY, R. S. D.; FERREIRA, M. A.; SILVA, E. A. Mobilidade social e empoderamento: a percepção das mulheres beneficiárias do programa Bolsa Família em Minas Gerais. Revista do Serviço Público, Brasília, v. 62, n. 4, p. 449-465, out/dez 2011.

MACAULAY, F. Trickling up, down and sideways: gender policy and political opportunity in Brazil. In: MAIER, E.; LEBON, N. (Orgs.). Women's activism in Latin America and the Caribbean: engendering social justice, democratizing citizenship. Rutgers
University Press, 2010.

MAHONEY, J.; THELEN, K. A theory of gradual institutional change. In: . (Orgs.). Explaining institutional change: ambiguity, agency and power. Cambridge, Cambridge University Press, 2010. p. 1-37.

MARQUES, D. Ativismo e participação: a situação de participação política das delegada da $4^{\mathrm{a}}$ Conferência Nacional de Políticas para Mulheres. In: MATOS, M.; ALVAREZ, S. E. O feminismo estatal participativo brasileiro. Volume I, Porto Alegre: Zouk, 2018. p. 201-224.

MCEVOY, D.; FÜNFGELD, H.; BOSOMWORTH, K. Resilience and climate change adaptation: the importance of framing. Planning Practice and Research, v. 28, n. 3, p. 280-293, 2013.

MENICUCCI, T. Público e privado na política de assistência à saúde no Brasil: atores, processos e trajetória. Rio de Janeiro, Editora Fiocruz, 2007.

. A política de saúde no governo Lula. Saúde e Sociedade, São Paulo, v.20, n.2, p.522-532, 2011.

MISKOLCI, R.; CAMPANA, M. "Ideologia de gênero": notas para a genealogia de um pânico moral contemporâneo. Sociedade e Estado, Brasília, v. 32, n. 3, p. 725-747, 2017.

PINHEIRO, M. Sobre a relação entre os movimentos feministas e o Estado no Brasil (2003-2014). 2015. 245 p. Tese (Doutorado em Ciência Política) Programa de Pós-Graduação em Ciência Política da Universidade Federal de Minas Gerais.

PIRES, R.; GOMIDE, A. Governança e capacidades estatais: uma análise comparativa de programas federais. Sociologia e Política, Curitiba, v. 24, n. 58, p. 121-143, 2016.

RAMOS, A.; FARIA, C. Las conferencias de políticas públicas en Brasil: hacia un sistema integrado de participación y deliberación a nivel nacional. Revista Española de Ciencia Política, n. 32, Julio, p. 43-63, 2013.

ROMÃO, W.; GURZA LAVALLE, A; ZAREMBERG, G. Political intermediation and public policy in Brazil: councils and conferences in the policy spheres of health and women's right. In: ZAREMBERG, G., et al. Intermediation and representation in Latin America: actors and roles beyond elections. New York: Palgrave Macmillan, 2017. p. 31-52.

SCHUMAHER, M. A. Os movimentos feministas ontem e hoje no Brasil: desafios da sua institucionalização. In: MATOS, M; ALVAREZ, S. Expressões feministas nas Conferências Nacionais de Políticas para as mulheres. Volume II. Porto 
Alegre: Zouk, 2018. p. 21-56.

SILVA, M. K.; et al. A dinâmica das relações sociais no Conselho Nacional de Saúde. In: CÔRTES, S. (Org.). Participação e saúde no Brasil. Rio de Janeiro: Fiocruz, 2009. p. 73-110.

SJÖSTEDT, M. Resilience revisited taking institutional theory seriously. Ecology and Society, v. 20, n. 4, p. 1-9, 2015.

SOARES, A.; SANTOS, N. Financiamento do Sistema Único de Saúde nos governos FHC, Lula e Dilma. Saúde em Debate, Rio de Janeiro, v. 38, n. 100, p. 18-25, 2014.

TILLY, C. Identity, boundaries \& social ties. Boulder, CO/Londres: Paradigm Publishers, 2005. 


\section{INSTITUTIONAL RESILIENCE: WHERE DOES PARTICIPATION GO IN THE NATIONAL COUNCILS OF HEALTH AND WOMENS'S RIGHTS?}

\author{
Debora Rezende de Almeida
}

\author{
RÉSILIENCE INSTITUTIONNELLE : OÙ VA \\ LA PARTICIPATION DANS LES CONSEILS \\ NATIONAUX DE LA SANTÉ ET DES DROITS DES \\ FEMMES?
}

\author{
Debora Rezende de Almeida
}

This article aims to understand the changes in political participation that have affected the relationship between the State and civil society in the public policies decision-making since the 2016 presidential impeachment in Brazil. For this, the article proposes the concept of institutional resilience, based on the combination of four types of literatures: studies dealing with resilience, institutional change, institutional participation and repertoires of collective action and interaction between state and social movements. Furthermore, it points out what are the factors that contribute to the resilience of some participatory institutions, based on the case study of the National Councils of Health and Women's Rights, and the use of qualitative research techniques, namely, semi-structured interviews, participant observation and content analysis, examining the changes in strategies and repertoires of interaction with the State, inside and beyond the councils, and raising questions about the future of institutional participation in the country.

KEYWORDS: Intitucional resilience, Institutional participation, National councils, Health, Women's rights.
Cet article vise à comprendre les changements dans la participation politique qui ont influencié la relation entre l'État et la société civile dans la la destitution présidentielle de 2016 au Brésil. À cette effect, l'article propose le concept de résilience institutionnelle, basé sur la combinaison de quatre objets littéraires: les études sur la résilience, le changement institutionnel, la participation institutionnelle et les répertoires d'action collective et d'interaction entre l'État et les mouvements sociaux. L'article souligne également quels sont les facteurs qui contribuent à la résilience de certaines institutions participatives, basé sur l'étude de cas des conseils nationaux pour la santé et les droits des femmes, et l'utilisation de techniques de recherche qualitative, à savoir, entretiens semi-structurés, l'observation participante et des données secondaires, examinant les changements des stratégies et des répertoires d'interaction avec l'État au sein et au-delà des conseils, et posant des questions sur l'avenir de la participation institutionnelle au Brésil.

Mots CLÉs: Résilience institutionnelle, Participation institutionnelle, Conseils nationaux, Santé, Droits des femmes. prise de décision des politiques publiques depuis

Debora Rezende de Almeida - Doutora em Ciência Política pela Universidade Federal de Minas Gerais (UFMG). Professora do Instituto de Ciência Política da Universidade de Brasília e integrante do Núcleo de Pesquisa RESOCIE (Repensando as relações Estado e sociedade), desenvolvendo pesquisas nas áreas de participação e representação política. Suas mais recentes publicações são: Civil society representation and digital accountability in Brazilian participatory institutions (Journal of Chinese Governance); Instituições participativas e repertórios de interação: os Conselhos Nacionais de Saúde e Assistência Social no contexto do impeachment (Revista do Serviço Público) e Claims of misrepresentation: a comparison of Germany and Brazil (Politics and Governance). 
Debora Rezende de Almeida

ERRATA

CADERNo CRH, Salvador, v. 33, 2020

No artigo RESILIÊNCIA INSTITUCIONAL: para onde vai a participação nos Conselhos Nacionais de Saúde e dos Direitos da Mulher?, com número de DOI: http://dx.doi.org/10.9771/ccrh.v33i0.33281, publicado no periódico Caderno CRH, vol. 33, 2020: elocation-id e020004, na página:

24 - Coluna 1

Onde se lia:

"INSTITUTIONAL RESILIENCE: WHERE DOWS PARTICIPATION GO IN THE NATIONAL COUNCILS OF HEALTH AND WOMENS'S RIGHTS?"

Leia-se:

"INSTITUTIONAL RESILIENCE: WHERE DOES PARTICIPATION GO IN THE NATIONAL COUNCILS OF HEALTH AND WOMEN'S RIGHTS?" 